\title{
Serial Monitoring and Hyperimmunoglobulin versus Standard of Care to Prevent Congenital Cytomegalovirus Infection: A Phase III Randomized Trial
}

\author{
Roland Devlieger $^{a}$ i Horst Buxmann ${ }^{b}$ Giovanni Nigro ${ }^{c}$ Martin Enders ${ }^{d}$ \\ Julia Jückstock ${ }^{e}$ Pal Siklós ${ }^{f}$ Andrea Wartenberg-Demand ${ }^{g}$ Jörg Schüttrumpf ${ }^{g}$ \\ Joachim Schütze ${ }^{g}$ Natascha Rippelg Marlis Herbold ${ }^{9}$ Gabriele Niemann ${ }^{9}$ \\ Klaus Friese ${ }^{\mathrm{h}}$

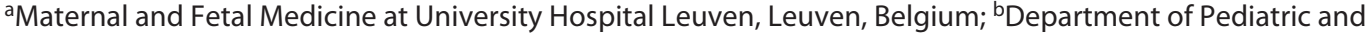
Adolescent Medicine, Division for Neonatology University Hospital Frankfurt, Frankfurt am Main, Germany;

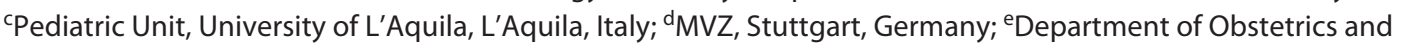
Gynecology, University Hospital, LMU Munich, Munich, Germany; 'Szent István Kórház (St. Stephan Hospital),

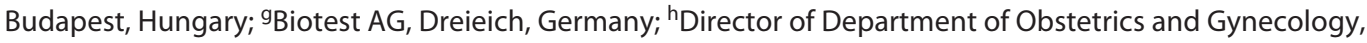
University Hospital, LMU Munich, Munich, Germany; 'Department of Obstetrics at GZA campus Sint-Augustinus, Wilrijk, Belgium
\end{abstract}

\section{Keywords}

Congenital cytomegalovirus · Maternofetal

cytomegalovirus transmission · Cytomegalovirus-specific hyperimmunoglobulin

\begin{abstract}
Introduction: Nonrandomized studies support the potential of cytomegalovirus hyperimmunoglobulin (CMV-Hyperlg) in preventing maternofetal CMV transmission, but prospective interventional studies show equivocal results. We present a prospective phase-III international randomized openlabel trial on the potential effect of CMV-Hyperlg following serial monitoring of CMV serostatus. Methods: CMV-seronegative pregnant women (gestational age $[G A]<14$ weeks) were 1:1 randomized to monthly CMV-serostatus monitoring and CMV-Hyperlg upon seroconversion (treatment), or routine prenatal care with CMV-serostatus testing at end of pregnancy (control). Ethical considerations required that control subjects with confirmed seroconversion be offered
\end{abstract}

karger@karger.com www.karger.com/fdt

Karger $\stackrel{\text { ' }}{5}$

BOPEN ACCESS
(C) 2021 The Author(s)

Published by S. Karger AG, Basel

This is an Open Access article licensed under the Creative Commons Attribution-NonCommercial-4.0 International License (CC BY-NC) (http://www.karger.com/Services/OpenAccessLicense), applicable to the online version of the article only. Usage and distribution for commercial purposes requires written permission.
Cytotect $^{\circledR}$. The primary endpoint was the proportion of fetuses/newborns with congenital CMV infection. Secondary endpoints included neonatal CMV disease and safety during the 24-month follow-up. Results: The treatment arm counted 4,800 randomized subjects: 52 seroconverted (median GA 24 [11-35] weeks), of which 45 completed follow-up. The control arm counted 4,735 randomized subjects: 42 seroconverted, of which 34 completed follow-up (evaluable data for 28 newborns) and 8 subjects chose off-label Cytotect ${ }^{\circledR}$. Congenital CMV rates were $13 / 28$ newborns $(46.4 \%$ [Cl 27.51 ; $66.13])$ vs. $16 / 45$ newborns $(35.6 \%$ [Cl $21.87 ; 51.22]$ ) in control and treated arms, respectively $(p=0.46)$. Newborn CMV disease was mostly mild and spontaneously resolving. There were no major safety concerns. The target sample was not reached within an acceptable time frame. Conclusions: Serial monitoring of CMV serostatus with CMV-Hyperlg treat-

Roland Devlieger and Horst Buxmann contributed equally to the manuscript.
Correspondence to:

Roland Devlieger, roland.devlieger@uzleuven.be Horst Buxmann, horst.buxmann@ mkkliniken.de 
ment was associated with a mild nonsignificant reduction in the vertical CMV transmission rate. Studies on the optimal preventive strategy are hampered by epidemiological and ethical challenges and should focus on GA-dependent transmission rates and accurate dating of infection.

(c) 2021 The Author(s).

Published by S. Karger AG, Basel

\section{Introduction}

Human cytomegalovirus (CMV) is the most common congenital infection in the developed countries, affecting up to $0.7 \%$ of all live births [1]. Approximately $11 \%$ of infected neonates are born with clinical disease and a 30$40 \%$ risk of long-term neurological sequelae [1-3], while asymptomatic neonates run a 6-23\% risk of developing hearing loss later in life [4]. In Europe, primary CMV infection occurs in $1-8 \%$ of pregnant women [5], with a maternofetal CMV transmission rate of $32 \%$ [1].

To date, routine screening for CMV seroconversion during pregnancy has not been recommended because other than hygiene measures $[6,7]$ - strategies proven effective in preventing vertical transmission have been unavailable [8]. Recently, however, Shara-Nissan et al. [9] reported on a first placebo-controlled randomized trial showing that oral Valacyclovir treatment can reduce the vertical transmission rate in 1st-trimester primary CMV infection. A more extensive body of research experience is available for CMV-specific hyperimmune globulin (CMV-HyperIg), but although nonrandomized studies have supported a potential benefit on the clinical outcome of infected neonates [10-16], evidence from prospective trials on the ability of CMV-HyperIg to prevent congenital CMV infection remains equivocal [17-20]. Whereas Nigro et al. [17] documented a significant $24 \%$-point reduction in the vertical transmission rate in a nonrandomized study, in 2 subsequent randomized placebo-controlled trials, Revello et al. [18] and Hughes [19] found a $14 \%$-point reduction and a $3 \%$-point increase, respectively, which were statistically nonsignificant. A meta-analysis showed an OR of 0.43 ( $p=0.006$ with little heterogeneity) toward a reduction in the vertical transmission rate $[21,22]$. Given its significant clinical and health-economic impact, the potential benefit of CMVHyperIg for congenital CMV has remained at the forefront of clinical research, with clinicians, epidemiologists, and biostatisticians agreeing that more specific prospective controlled trials are needed [23].

Along this line, in 2008 we initiated a randomized open-label multicenter international phase III trial to in- vestigate the initially reported preventive effect of CMVHyperIg on CMV vertical transmission by Nigro et al. [17] in a cohort of seronegative women who underwent systematic monitoring of CMV serostatus during pregnancy. Here, we present the results of this trial, and we discuss the challenges and focus points that will need to be considered in future studies on the potential of CMVHyperIg to prevent fetal CMV infection.

\section{Materials and Methods}

\section{Study Design}

This prospective randomized open-label phase-III study was conducted at 137 recruitment and 16 treatment centers across Austria, Belgium, Germany, Hungary, and Italy (EudraCT 2007004692-19) (see online suppl. material; for all online suppl. material, see www.karger.com/doi/10.1159/000518508). All local ethics committees approved the study, which was conducted in accordance with the International Council for Harmonization Good Clinical Practice guidelines, Declaration of Helsinki, and each country's legal requirements. All participants provided written informed consent. Standard hygiene counseling was given on CMV infection prevention. Data management and analysis were performed by GKM (Munich, Germany) and ICRC-Weyer GmbH (Berlin, Germany). The CONSORT statement is provided as online suppl. material.

Pregnant women aged 18-45 were screened for CMV-specific IgG serostatus at gestational age $(\mathrm{GA})<14$ weeks (Fig. 1). Inclusion and exclusion criteria are provided as online suppl. material. CMV IgG-seronegative women were 1:1 randomized, to (i) 4-weekly prospective CMV IgG monitoring until GA 36 weeks +6 days with - in the event of seroconversion - treatment with CMV-HyperIg (treatment group), or (ii) standard prenatal care followed by 1 single CMV IgG serology test at GA 36 weeks +6 days (control group): CMV serology was performed earlier only if clinical suspicion of primary CMV infection arose, whereby - if seroconversion was confirmed - off-label treatment with Cytotect ${ }^{\circledR}$ Biotest was offered for ethical reasons (off-label group). Clinical suspicion of maternal CMV infection was defined as the occurrence of maternal clinical symptoms consistent with CMV infection or the finding of fetal abnormalities suggestive of CMV infection on routine prenatal ultrasounds scans. At screening, pregnant women were assigned a unique subject number in chronological order of enrollment; subjects found to be seronegative were randomized prior to seroconversion. The randomization was performed by the contract research organization GKM using a centralized randomization procedure and a computer-generated list generated with SAS-software (PRCO PLAN procedure). The respective treatment group for the subject was faxed to the recruitment centers after the subject was enrolled. The study was not blinded. Newborns were followed prospectively until 24 months of age. Amniocentesis was performed when medically indicated and at the investigator's discretion. Fetal and congenital CMV infections were defined as the presence of CMV DNA in amniocentesis fluid or newborn urine within 7 days of birth, respectively. If the fetal infection was diagnosed, the decision for treatment, including off-label CMV- 


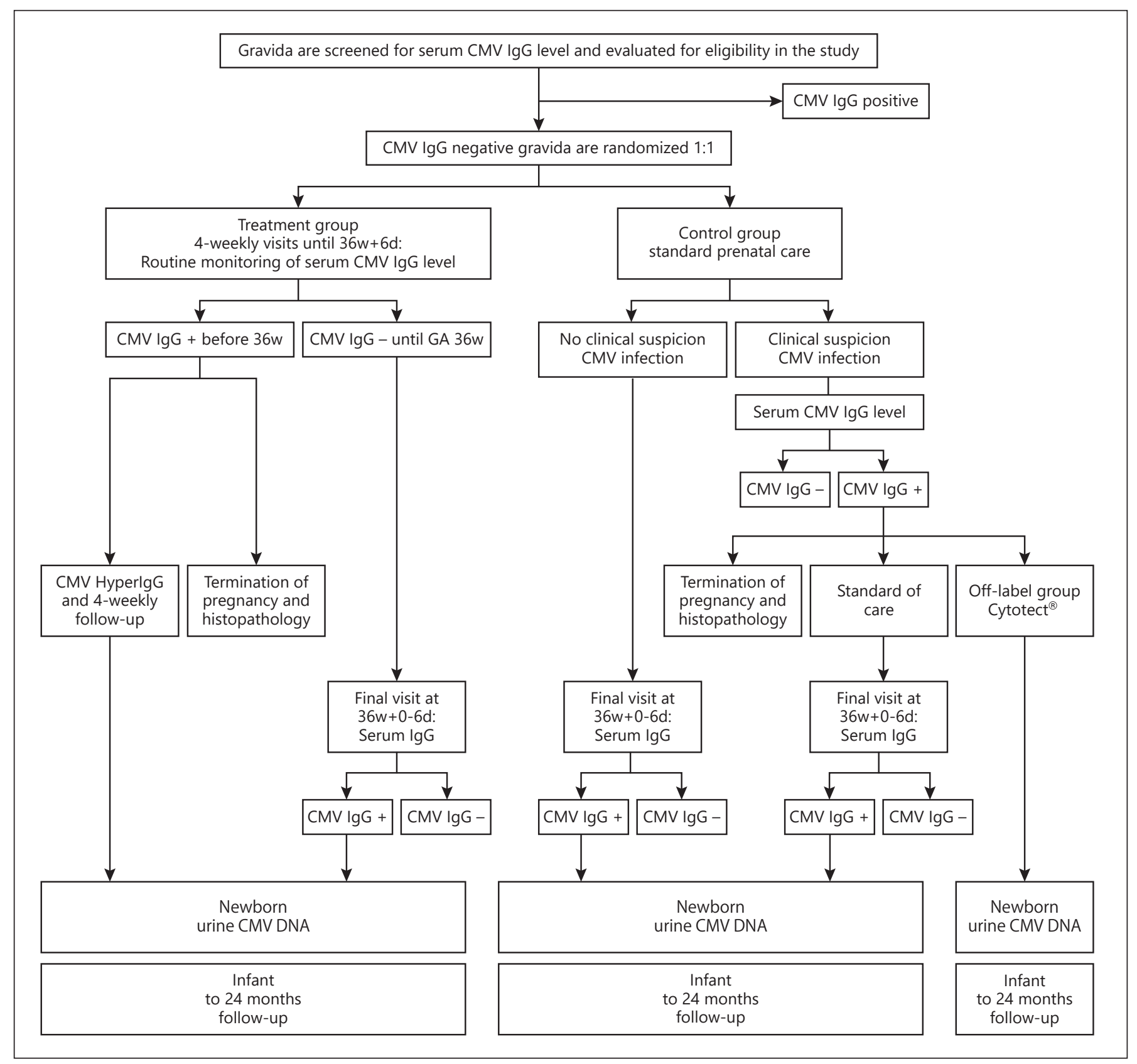

Fig. 1. Study design. CMV, cytomegalovirus.

HyperIg treatment, was at the discretion of the pregnant woman. Laboratory analyses were centralized in the Laboratory Enders \& Partners (Stuttgart, Germany).

\section{CMV-Specific HyperIg}

The CMV-HyperIg solution was BT094 (Biotest Pharma $\mathrm{GmbH}$, Dreieich, Germany), containing $50 \mathrm{mg} / \mathrm{mL}$ human plasma protein consisting of $>95 \%$ IgG and $>70 \mathrm{U} / \mathrm{mL}$ CMV-specific IgG. A dose of $200 \mathrm{U} / \mathrm{kg}$, administered intravenously at maximally 0.8 $\mathrm{mL} / \mathrm{kg} / \mathrm{h}$, was given twice with an interval of 14 days; an optional third dose was given 28 days later, guided by $\operatorname{IgG} / \mathrm{IgG}$ avidity levels (see "Laboratory Analyses").

\section{Study Endpoints}

The primary end point was the proportion of CMV-infected fetuses/newborns of seroconverted mothers in the treated versus the control group. Secondary endpoints were prospective CMVseroconversion rate, serum CMV IgG/IgG avidity levels during and after treatment, and the safety of CMV-HyperIg. Secondary endpoints for the newborns were CMV IgG, IgM, and IgG avidity 
Table 1. Baseline characteristics of study subjects

\begin{tabular}{|c|c|c|}
\hline Parameter & Treatment $(n=45)$ & Control $(n=35)$ \\
\hline Age, median (range), years & $30(22 ; 39)$ & $30(18 ; 39)$ \\
\hline Mean (SD) & $29.9(4.2)$ & $30.5(4.3)$ \\
\hline Parity, $n$, median (range)* & $1(0 ; 3)$ & $1(0 ; 6)$ \\
\hline Mean (SD)* & $1.1(0.7)$ & $1.2(1.1)$ \\
\hline Age youngest child, median (range), years ${ }^{\dagger}$ & $1(0 ; 5)$ & $1(0 ; 9)$ \\
\hline Mean $(\mathrm{SD})^{\dagger}$ & $1.4(0.9)$ & $1.9(1.8)$ \\
\hline Gestational age at screening, median (range), weeks & $12(4 ; 13)$ & $11(5 ; 13)$ \\
\hline Mean (SD) & $10.9(2.6)$ & $10.1(2.4)$ \\
\hline Gestational age at seroconversion, median (range), weeks & $24(11 ; 35)$ & $\mathrm{N} / \mathrm{A}$ \\
\hline Mean (SD) & $23.5(6.9)$ & N/A \\
\hline \multicolumn{3}{|l|}{ Country, $n(\%)$} \\
\hline Austria & $1(2.2)$ & $3(8.6)$ \\
\hline Belgium & $36(80.0)$ & $17(48.6)$ \\
\hline Germany & $7(15.6)$ & $14(40.0)$ \\
\hline Hungary & $1(2.2)$ & $1(2.9)$ \\
\hline Italy & - & - \\
\hline Gestational age at delivery, median (range), weeks & $39(35 ; 41)$ & $39(36 ; 41)$ \\
\hline Mean (SD) & $39.1(1.2)$ & $38.8(1.5)$ \\
\hline Newborn female/male ratio, $n / n^{\ddagger}$ & $20 / 25$ & $15 / 10$ \\
\hline
\end{tabular}

N/A, not applicable: could not be determined on the basis of study design. ${ }^{*} n=1$ missing data in the control group. ${ }^{\dagger} n=7$ missing data in treatment and control groups. ${ }^{\ddagger} n=10$ missing data in the control group.

levels, and clinical symptoms/signs of CMV disease at birth and during the 24-month follow-up.

\section{Laboratory Analyses}

Screening CMV IgG tests were done using ARCHITECT CMV IgG immunoassay (Abbott, Germany). IgG seroconversion prompted CMV-IgM and IgG avidity (ARCHITECT), CMV-IgMELA Test PCS (Medac GmbH, Wedel, Germany), and CMV IgG avidity VIDAS (bioMérieux, Switzerland). During CMV-HyperIg treatment, IgG/IgG avidity were monitored using CMV IgG RecomBlot (MIKROGEN, Germany) and anti-hCMV recombinant gB IgG ELISA (Biotest, Germany), before and 1-3 days after each dose, and monthly thereafter. An optional third dose was recommended if - 1 month after the second dose - antibodies to CMV-gB (ELISA and/or immunoblot) decreased significantly and/or RecomBlot CMV-IgG avidity changed from moderate to low. Amniotic fluid and newborn urine/blood were tested for CMV-DNA using QIAGEN PCR (Hilden, Germany) and for CMV early nuclear antigen in rapid cell culture using standardized in-house methods.

\section{Clinical Follow-Up and Safety}

Women in the treatment group were followed with medical history, physical examination, and European Federation of Societies for Ultrasound in Medicine and Biology (EFSUMB) level II/III obstetric ultrasound at every study visit, and in the control group with the local standard of prenatal care. Infants were followed with physical examination, pediatric EFSUMB level II/III brain, liver and kidney ultrasound, otoacoustic emissions, fundoscopy, and neurodevelopmental assessment (Bayley cognitive/motor scale) within 7 days of birth and thereafter at 6, 12, and 24 months. In the treatment arm, adverse events (AEs) were prospectively docu- mented; in the control arm, AE collection was done retrospectively. Treatment-emergent AEs (TEAEs) in the treated arm were defined as occurring after the first CMV-HyperIg dose, and in the control group after confirmed seroconversion.

\section{Statistical Analyses}

Considering the 24\%-point reduction in the congenital CMV infection rate reported by Nigro et al. [17], and an assumed $60 \%$ CMV seroprevalence and $1 \%$ seroconversion rate during pregnancy in the participating countries [24-27], we estimated that a confirmatory 2 -sided $\chi^{2}$ analysis ( $\alpha=0.05,80 \%$ power) would require at least 49 evaluable subjects per study arm and an estimated 25,000 pregnant women to be screened. However, the study was prematurely terminated after 8 years due to slow accrual of evaluable study subjects. An exploratory primary endpoint analysis was performed using a 2 -sided Fisher's Exact test $(\alpha=0.05)$. Secondary endpoints were subjected to exploratory analyses, including a post hoc analysis within the subgroup of congenitally CMV-infected fetuses/infants.

\section{Results}

\section{Study Subjects}

Participants were enrolled between October 2008 and September 2014; the final newborn study visit dated December 2016. Baseline characteristics of study subjects were similar between groups (Table 1). Subject disposition is shown in Figure 2. The CMV seropositivity in the 


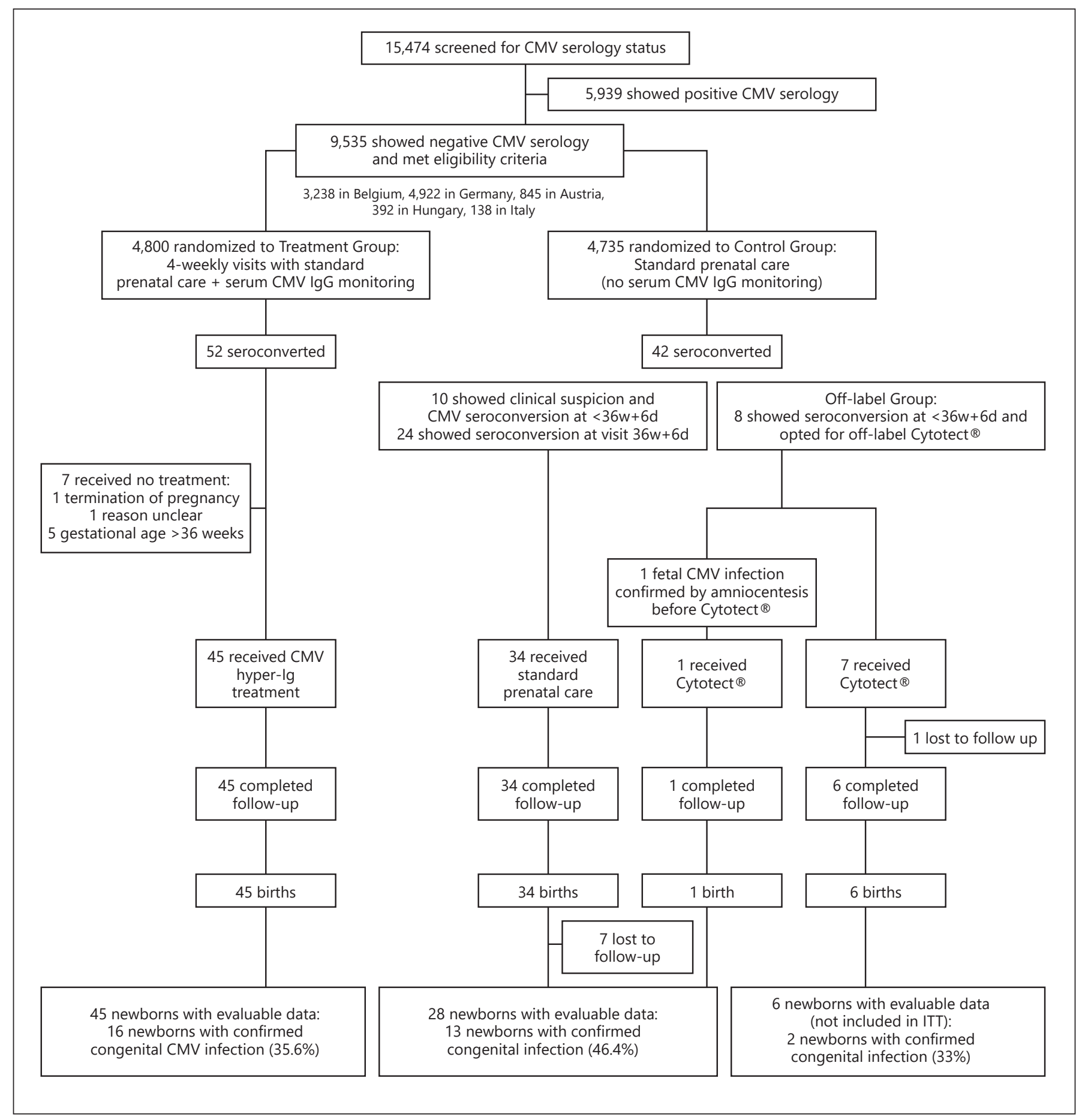

Fig. 2. Disposition of study subjects. Primary and secondary endpoint analyses were performed on the ITT set, which included all 45 subjects from the treatment group who completed treatment, all 34 subjects from the control group, and 1 subject from the off-label group in whom the primary endpoint (fetal CMV infection confirmed on amniocentesis) was reached before off-label Cytotect ${ }^{\circledR}$ treatment was started. Safety analyses were performed on the safety set, which included 45 subjects from the treatment group, 34 subjects from the control group, and 8 subjects from the off-label group. ITT, Intention-To-Treat; CMV, cytomegalovirus. 
Table 2. CMV serology status in pregnant women at confirmation of seroconversion (ITT set)

\begin{tabular}{|c|c|c|c|c|}
\hline \multirow[t]{2}{*}{ Serology parameter } & \multirow{2}{*}{$\begin{array}{l}\text { Treatment } \\
(n=45)\end{array}$} & \multicolumn{2}{|l|}{ Control $(n=35)$} & \multirow{2}{*}{$\begin{array}{l}\text { Off-label } \\
(n=7)\end{array}$} \\
\hline & & $\begin{array}{l}\text { seroconversion } \\
\text { confirmed during } \\
\text { pregnancy }\end{array}$ & $\begin{array}{l}\text { seroconversion } \\
\text { confirmed at final } \\
\text { study visit }\end{array}$ & \\
\hline \multicolumn{5}{|l|}{ CMV lgG } \\
\hline Analyzable result, subjects (\%) & 45 & 11 & 24 & 7 \\
\hline Positive titer, subjects, $n(\%)$ & $45(100)$ & $11(100)$ & $24(100)$ & $7(100)$ \\
\hline Negative titer, subjects, $n(\%)$ & 0 & 0 & 0 & $0(0)$ \\
\hline \multicolumn{5}{|l|}{ CMV IgG avidity } \\
\hline Analyzable result, subjects (\%) & 35 & 10 & 22 & 6 \\
\hline Low avidity, subjects, $n(\%)$ & $35(100)$ & $8(80)$ & $19(86)$ & $6(100)$ \\
\hline High avidity, subjects, $n(\%)$ & 0 & $2(20)$ & $3(14)$ & $0(0)$ \\
\hline \multicolumn{5}{|l|}{ CMV-AK IgM } \\
\hline Analyzable result, subjects (\%) & 45 & 11 & 24 & 5 \\
\hline Equivocal result, subjects, $n(\%)$ & 0 & $1(9)$ & $4(17)$ & $1(20)$ \\
\hline Positive titer, subjects, $n(\%)$ & $45(100)$ & $8(73)$ & $17(71)$ & $4(80)$ \\
\hline Negative titer, subjects, $n(\%)$ & 0 & $2(18)$ & $3(13)$ & $0(0)$ \\
\hline
\end{tabular}

ITT, Intention-To-Treat; CMV, cytomegalovirus.

screened population was $38 \%$ and the seroconversion rate in the study population was $0.99 \%$. For all seroconverted subjects, a full serology test verified recent primary CMV infection (Table 2). The treatment arm counted 52 subjects: 45 completed the study protocol, while 7 subjects did not receive treatment (Fig. 2). Four subjects underwent amniocentesis, 1 of which showed a positive CMV DNA PCR; all 4 subjects received CMV-HyperIg treatment as per protocol. Of 45 subjects in the treatment group, 1 subject received 1 dose, 8 received 2 doses, and 36 received 3 doses. Eight subjects gave birth or reached GA of 38 weeks before a second $(n=1)$ or third follow-up visit $(n=7)$ was due; in 1 subject who received 2 doses, the follow-up serology sample was unavailable. All 36 remaining subjects received a third dose as guided by follow-up CMV-gB ELISA IgG titer and RecomBlot CMVIgG avidity. For IgG titer, analyzable data for the $2 \mathrm{com}$ parative time points were available for $34 / 36$ subjects: 1 subject showed a persistently high titer, whereas the other 33 showed a significant decrease (median relative decrease in the IgG index value was 50\% [range 25-83\%]; median absolute IgG index value was 4.5 [range 3-9]) on day 1 after the second dose, versus 2 (range 1-4) at month 1 after the second dose. For IgG avidity, analyzable results were available for 15 subjects: 8 showed a decrease in avidity, 2 showed persistently low avidity, whereas only 5 showed persistently high avidity. At the subject level, considering both IgG titer and avidity results combined, all
36 subjects met the IgG titer and avidity recommendation for a third dose.

The control arm counted 42 subjects: 34 received routine prenatal care (control), while 8 chose to receive off-label Cytotect ${ }^{\circledR}$ treatment (off-label). For 24 of 34 control subjects, seroconversion was documented at the final 36 weeks +6 days visit, whereas for 10 subjects, seroconversion was documented earlier when clinical suspicion arose. All 34 completed the study until birth, but 7 were subsequently lost to follow up. In the offlabel group, 4 subjects underwent amniocentesis; in 1 of these, a positive CMV DNA PCR confirmed fetal CMV infection; all 4 chose to receive off-label treatment with Cytotect ${ }^{\circledR}$.

\section{Primary Endpoint: Congenital CMV Infection}

Congenital CMV infection was confirmed in 13 of 28 infants $(46.4 \%$ [CI 27.51; 66.13]) from the control group, and in 16 of 45 infants $(35.6 \%$ [CI $21.87 ; 51.22])$ from the treated group, constituting an $11 \%$ point difference $(23 \%$ relative reduction) that was not statistically significant ( $p$ $=0.46$, Fisher's exact). The post hoc calculated study power was $11.6 \%$. In subgroup analyses, congenital infection rates among women who started treatment before GA 20 weeks were $3 / 14$ subjects $(21.4 \%$ [CI 4.66 ; $50.80]$ ), in contrast to $13 / 31$ subjects among women who started treatment after 20 weeks ( $41.9 \%$ [CI 24.55; 60.92]). The seroconversion rate in the off-label group was $33 \%$. 
Table 3. Clinical outcome of infants born to study subjects

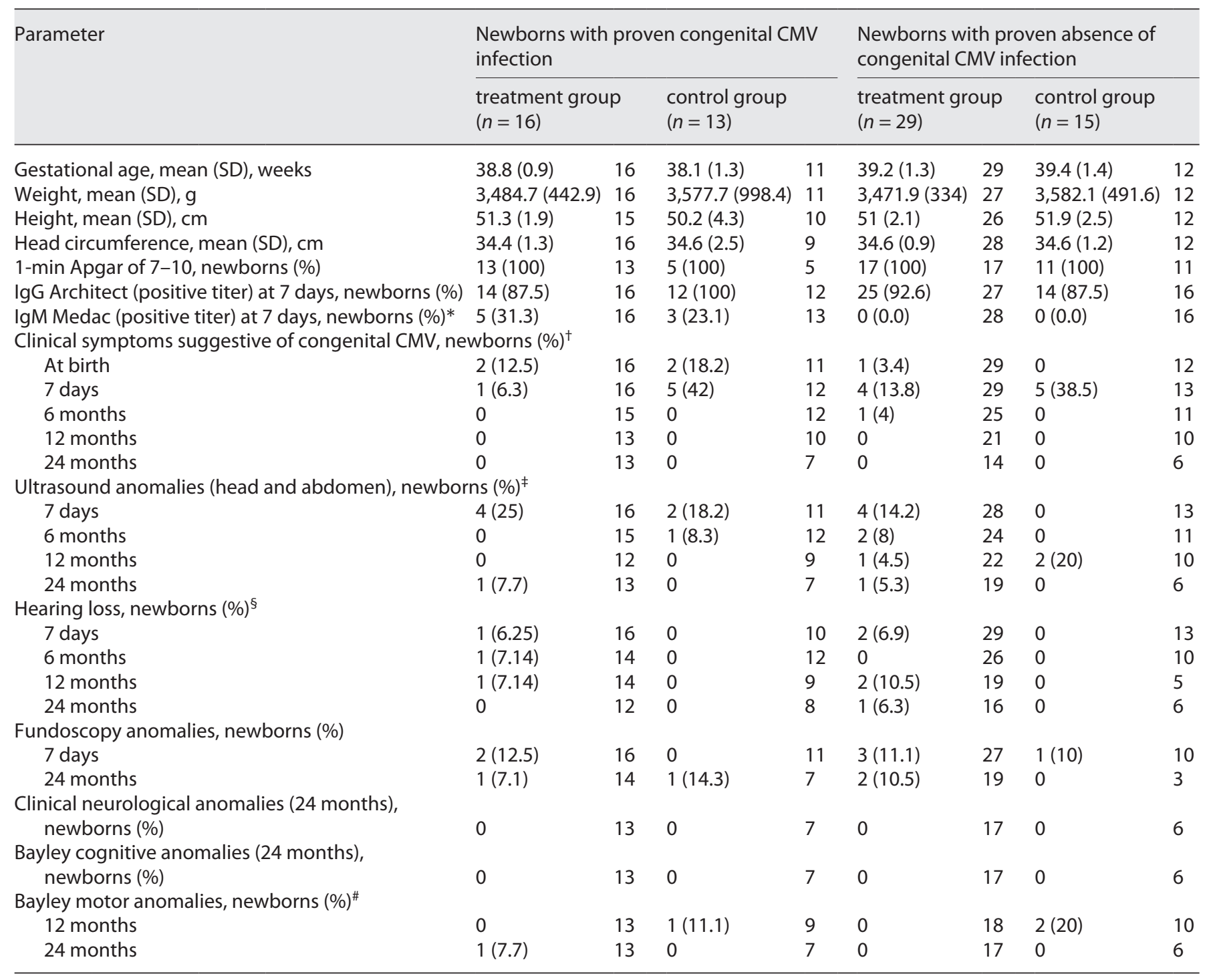

Findings in the CMV-infected/treated group were: retinal hemorrhages in $n=2$ (7 days) and congenital hypertrophy/retinal pigmentation in $n=1$ (24 months); in the CMV-infected/control group: mild astigmatism in $n=1$ ( 24 months); in the noninfected/treated group: bilateral microphthalmia and sclerocornea (7 days) and navigation visus left (24 months) in $n=1$, astigmatism ( 24 months) in $n=1$, hyperopia and bilateral astigmatism ( 7 days) in $n=1$, and perinatal peripheral punctate retinal bleeding ( 7 days) in $n=1$; and in the noninfected/control group: postnatal preretinal bleeding (7 days) in $n=1$. CMV, cytomegalovirus. *Equivocal test result in $n=1$ (proven CMV infection, treated), $n=1$ (proven infection, control), $n=6$ (noninfected, treated), and $n=3$ (noninfected, control). 'Symptoms mostly concerned jaundice, abnormal tone, and petechiae. ${ }^{\ddagger}$ Anomalies concerned mostly splenomegaly, kidney anomalies, and intracranial lesions. ${ }^{\S}$ Isolated hearing loss (in the absence of otitis serosa or otitis media). "Bayley II motor showed hyperlaxity with bottom shuffling in 1 infected subject from the control group (12 months), and mild developmental delay in 1 infected subject from the treatment group at 24 months.

The GA at which seroconversion was documented ranged between 14 weeks, 2 days and 32 weeks, 4 days; for the 2 subjects who showed maternofetal transmission, the GA at seroconversion was 32 weeks and 32 weeks +4 days.

Serial Monitoring and HyperIg to Prevent Congenital CMV

\section{Clinical Follow-Up of Infants}

Table 3 shows the clinical outcome of infants for the $\mathrm{CMV}$-infected and CMV-noninfected subgroups and a by-subject clinical course of the infected infants is given in Table 4. Across infected and noninfected subgroups, 


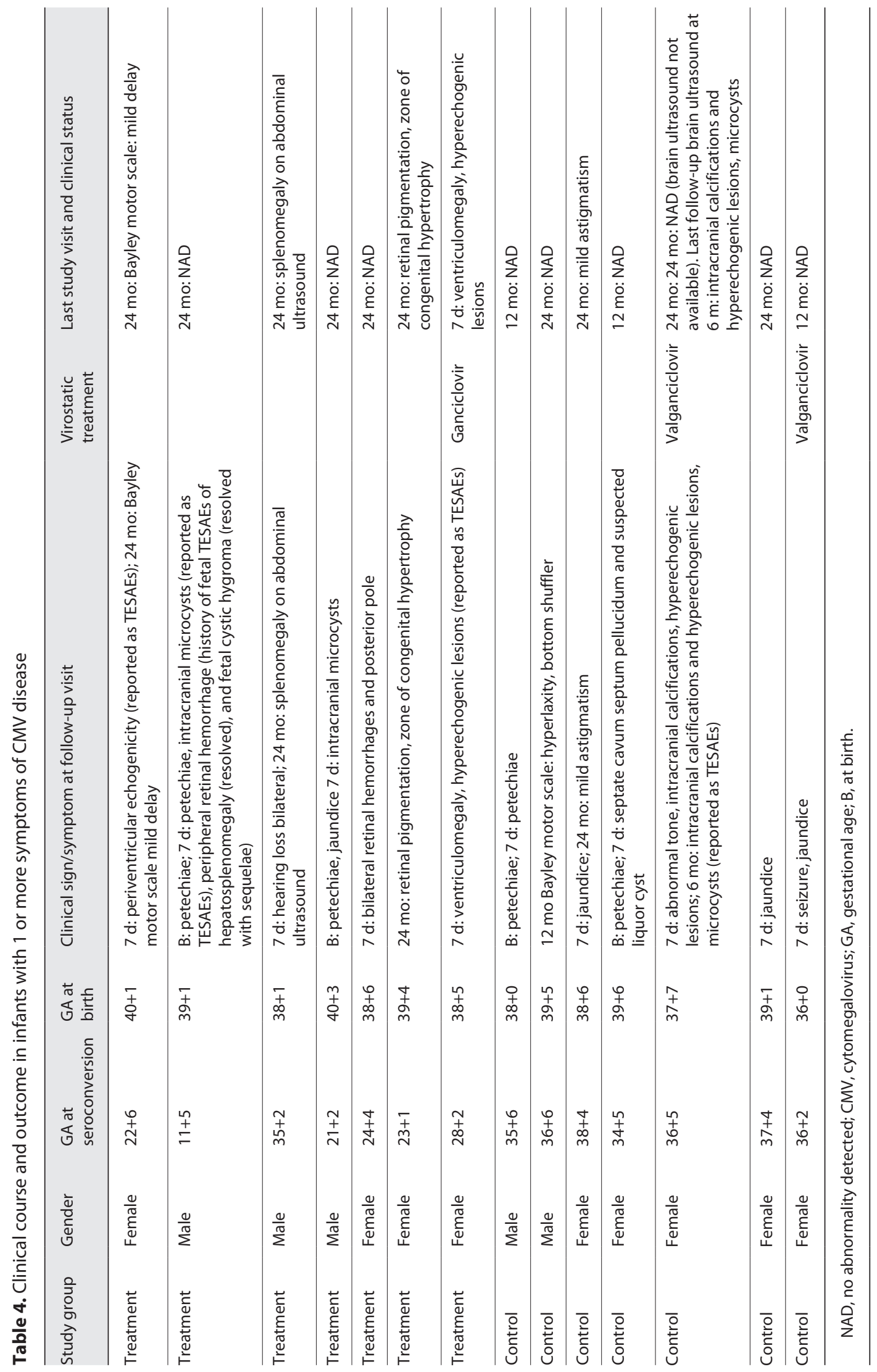


Table 5. Adverse events in pregnant women

\begin{tabular}{|c|c|c|c|c|c|c|}
\hline Adverse event type & total events & $\begin{array}{l}\text { subjects with } \geq 1 \\
\text { event (\%) }\end{array}$ & total events & $\begin{array}{l}\text { subjects with } \\
\geq 1 \text { event (\%) }\end{array}$ & total events & $\begin{array}{l}\text { subjects with } \\
\geq 1 \text { event (\%) }\end{array}$ \\
\hline Adverse events & 108 & $32(71.1)$ & 20 & $10(29.4)$ & 3 & $2(25)$ \\
\hline Treatment-emergent adverse events & 91 & $30(66.7)$ & 15 & $9(26.5)^{\dagger}$ & 0 & 0 \\
\hline Related to treatment* & 19 & $11(24.4)$ & 6 & $4(11.8)$ & 0 & 0 \\
\hline Serious and related to treatment & 0 & 0 & 0 & 0 & 0 & 0 \\
\hline
\end{tabular}

CMV-Hyperlg, cytomegalovirus hyperimmunoglobulin. * Treatment being: CMV-Hyperlg in the treatment group, routine prenatal care in the control group, and Cytotect in the off-label group. ${ }^{\dagger}$ In 1 subject, AEs were reported after informed consent but before confirmation of seroconversion.

the number of neonates in follow-up and therefore also the number of clinical study visits were higher in the treated than in the control group. All but 1 infant (from the infected control group, see Table 3) had biometrics considered normal according to WHO growth standards [26]: born prematurely (GA 36 weeks +2 days) with severe IUGR and jaundice, the infant showed full catch-up growth by month 6 . In the infected group, clinical symptoms suggestive for congenital CMV were observed no later than day 7 , at which point they were 8 -fold more frequent in infected infants from the control than that in the treatment group. Anomalies on cranial and abdominal ultrasound were mostly solitary findings documented on day 7 visits, slightly more frequent in the treatment than in the control group and occurring in both infected and noninfected subjects. Hearing loss was detected 8 times in the treatment group but persisted until 24 months only in 1 noninfected infant. Fundoscopy at the 7-day and 24-month visits showed few isolated anomalies, slightly more frequent in the treatment than in the control group and both in noninfected and infected subjects. Clinical neurological and Bayley cognitive anomalies were documented in neither group, and Bayley motor assessment showed mild deflections in 1 infant in each group. Three infants ( 1 treated, 2 control) received antiviral treatment.

\section{Safety}

Table 5 shows the frequency and types of AEs in the treatment and control groups; in neither group occurred TESAEs that were considered treatment-related, or TEAEs that led to study withdrawal or a fatal outcome. The TESAEs, which are shown in detail in online suppl. Table 1, included cesarean section in 9 treated (20\%) and
4 control subjects (12\%), and premature labor in $4(9 \%)$ treated subjects. The most frequently reported TEAEs included fatigue, headache, and minor respiratory disorders in 15 treated subjects, of which 6 events were considered treatment-related.

Overall, in the treated group, there were 5 occurrences of preterm labor (11\%), 4 of which were considered a TESAE: these occurred weeks to months after CMV-HyperIg administration, and 2 of them required tocolytic treatment, but none of these subjects delivered prematurely. There was 1 preterm delivery in 1 other subject of the treated group (2\%) and in 2 subjects of the control group (5\%).

AEs reporting during fetal and 24-month infant follow-up (online suppl. Tables 2, 3) showed total TEAE counts to be higher in the treated group (protocol with 4-weekly prenatal visits and fetal ultrasound) than in the control group (protocol with standard prenatal care), with a 4 -fold and a 1.5-fold increase, respectively. The difference in TEAE incidence was less pronounced, with a slight 1.3- and 1.4-fold increase, respectively. Overall, no new serious AEs were documented, and none of the AEs led to withdrawal or death of study subjects.

\section{Discussion}

This phase-III randomized trial in pregnant women undergoing serial monitoring of CMV serostatus followed by CMV-HyperIg treatment documented a $23 \%$ relative reduction in the maternofetal CMV transmission rate that was not statistically significant relative to that in pregnant women undergoing routine prenatal care. Sim- 
ilar to Revello et al. [18], the study showed a qualitatively similar effect but did not achieve the statistical power to confirm the $60 \%$ relative reduction reported by Nigro et al. [17]. All 3 studies contrasted with the absence of any effect reported by Hughes [19]. The variability in effect size and heterogeneity in the study design reveal aspects of the epidemiology, infectiology, and research ethics of primary CMV infection during pregnancy that need careful consideration in studies on the prevention of congenital CMV.

This trial is the first to also prospectively monitor long-term clinical outcome in the off-spring of pregnant women who were serially monitored for CMV seroconversion and subsequently treated with CMV-HyperIg. The 8-fold higher frequency of CMV disease symptoms among infected infants in the control group on day 7 seemed to concur with reports, suggesting that CMVHyperIg treatment may attenuate clinical manifestations of congenital CMV-infection [12-15, 17]. However, these findings should be interpreted with caution because of the nonblinded character of the study. Moreover, a follow-up of clinical and subclinical signs showed that across the 2 groups, CMV disease was generally mild and mostly resolved spontaneously within 24 months, probably because few infections occurred in the 1st trimester when neonatal disability from CMV transmission is greater [28-31]. Few infected infants required antiviral treatment or showed a mild isolated symptom at a 24-month follow-up and were similarly distributed over both groups.

Safety parameters should be interpreted with caution. The study design was nonblinded, with prospective $\mathrm{AE}$ collection in the treatment and retrospective AE collection in the control arm. Since such would favor the control group, these biases were accepted. Expectedly, TEAE and TESAE rates were higher in treated than in the control group, but none were fatal or led to study withdrawal. The most frequent TEAEs in the treated group included fatigue and headache, which are known side effects of hyperimmunoglobulin therapy and which were attributed according to the treatment, as well as minor upper airway conditions. Given their nature, these events may be attributed also in part to reporting bias. Cesarean section was the most frequent TESAE in both groups; however, the order of magnitude was similar and fell below the estimated rates for Western Europe [32]. Revello et al. [18] cautioned for a higher (although nonsignificant) rate of obstetric complications in HyperIg-treated women. Here, the discordance in preterm labor rates may be due to underreporting bias in the control group; reassuringly, however, despite the known association of congenital CMV with premature birth [1], preterm delivery rates for both groups fell far below the estimates for Western Europe [33]. The multilevel reporting bias may also explain the variations in $\mathrm{AE}$ rates in fetuses. Higher numbers of prenatal visits and fetal ultrasounds in the treated group may account for the variation in total TEAEs, and an assumed subjective reporting bias by nonblinded physicians and study participants may have contributed further. Between and within subgroups of infected and noninfected infants, TEAE incidences were similar, suggesting that AEs were not related to infection and that CMV-HyperIg is safe for the fetus and neonate.

Despite a sizeable screened population and despite the $38 \%$ seroprevalence and $0.99 \%$ seroconversion rates that were consistent with the reported ranges in Europe $[5,17$, $34,35]$, the accrual of study subjects was slow. Also, ethical considerations of the severity of congenital CMV, the availability of marketed Cytotect ${ }^{\circledR}$, and the favorable outcome reported by Nigro et al. [17] precluded a placebocontrolled design and necessitated an off-label control arm. Interestingly, although small sample sizes preclude meaningful conclusions, the transmission rate in the offlabel and treated arm was similar. Last, the inevitable problem of dropouts in a long-term study further compromised our target sample, resulting in a limited post hoc statistical power of $11.6 \%$.

Observation of the between-trial variation in study populations revealed potential confounding factors in evaluating the clinical effect size of serial monitoring with CMV-HyperIg treatment. Because maternofetal CMV transmission risk is GA-dependent, varying from $30 \%$ in the first to $72 \%$ in the third trimester [29], and because, at dose regimens studied so far, CMVHyperIg establishes a reduction rather than a complete prevention of vertical transmission $[17,18]$, one may expect a clinical effect size to also vary with GA. The mean GA at seroconversion in our treated group (24 weeks) was markedly higher than in the other trials [17-19], which probably accounts for the higher baseline and posttreatment residual transmission risk, and which may also explain the lower pregnancy termination rate (1.9\%). Along this line, the transmission rate remained higher in women who seroconverted after, rather than before, 20-week GA. Kagan et al. [20] reported a $7.5 \%$ transmission rate in CMV-HyperIgtreated women with first-trimester primary CMV infection, as opposed to $35.2 \%$ in nontreated matched 
historical controls. Similarly, Shahar-Nissan et al. [9] documented the first-trimester CMV transmission rate to decline from $30 \%$ to $11 \%$ with oral Valaciclovir, an effect that seemed to exclude periconception infections. Importantly, although nonrandomized and uncontrolled, Kagan et al. [20] minimized variability by defining a homogeneous risk profile in first-trimester gravida with specific laboratory evidence of very recent-onset CMV infection. Variability within and between studies is indeed further complicated by differences in methods to date CMV infection. Although recent-onset CMV infection was confirmed in all subjects [36], our study design precluded exact dating of infection in our control group. Interventional trials should prioritize accurate dating of infection-onset for subsequent reliable GA-matched comparisons, for example, with epitope-specific IgG/M avidity assays and missing anti-gB2 IgG reactivity [20,37]. Last, the favorable effect seen by Kagan et al. [20] may also be attributed to the higher dose regimen. Whereas prior trials used monthly $100 \mathrm{mg} / \mathrm{kg}$ doses [17-19], Kagan advocated 2-weekly $200 \mathrm{mg} / \mathrm{kg}$ infusions up to 20 week GA, based on a pharmacokinetic study. We used a similar $200 \mathrm{U} / \mathrm{kg}$ dose, based on prior studies from, and personal communications with Nigro et al. [17] team $[17,38]$, and we administered infusions at 2 - to 4 -week intervals, assuming that 6 weeks beyond primary infection, maternal IgG, and IgG avidity maturation responses would sufficiently protect the fetus [36]. Follow-up serology at 1 month after the second dose showed a significant decline in IgG titers in almost all subjects with variable changes in IgG avidity, indicating that 3 doses of $200 \mathrm{U} / \mathrm{kg}$ would be a minimum to maintain protective levels beyond a 6 -week interval.

In conclusion, in this phase III RCT, treatment with CMV-HyperIg for prospectively diagnosed CMV primo-infections in - mostly 2 nd and 3rd trimester - serially monitored pregnant women showed a mild nonsignificant reduction in congenital CMV. Heterogeneity in the infectious profile and pregnancy characteristics of study subjects within and between studies may conceal the existence of relevant GA-specific clinical effects of CMV-HyperIg on maternofetal transmission. While placebo-controlled trials in pregnant women with CMV primo-infection face important epidemiological and ethical challenges, further studies on the optimal preventive strategy are warranted and should address GAdependent transmission rates and accurate dating of infection.

Serial Monitoring and HyperIg to Prevent

Congenital CMV

\section{Acknowledgments}

We thank all women and children who participated in the trial, all investigators, and medical staff who made this trial possible and An Billiau, MD, PhD, Celsus Medical Writing LLC, for her excellent support in the preparation of the manuscript.

\section{Statement of Ethics}

This study was conducted in accordance with the International Council for Harmonization Good Clinical Practice guidelines, Declaration of Helsinki, and each country's legal requirements. All participants provided written informed consent. The study protocol was reviewed and approved by all Local Ethics Committees at the participating institutions (coordinating investigator's Ethics Committee: Faculty of Medicine at Ludwig-Maximilians-Universität Munich; approval number 310-07).

\section{Conflict of Interest Statement}

H. Buxmann reports grants and personal fees from Biotest, Dreieich, Germany, during the conduct of the study; other from European Society of Pediatric Infectious Diseases; grants and personal fees from MSD Sharp \& Dohme GmbH, Haar, Germany; grants and personal fees from Biotest, Dreieich, Germany; grants and personal fees from Hoffmann-La Roche Ltd., Basel, Switzerland, outside the submitted work; and a member of the scientific advisory board of German CMV support group and ICON - Initiative for the Prevention Congenital CMV-Infection. R. Devlieger reports grants from Biotest company, during the conduct of the study. J. Jückstock reports grants from Biotest Company, during the conduct of the study. A. Wartenberg-Demand, J. Schüttrumpf, J. Schütze, N. Rippel, M. Herbold, and G. Niemann are full-time employees at Biotest, Dreieich, Germany. G. Nigro, M. Enders, P. Siklós, and K. Friese have nothing to disclose.

\section{Funding Sources}

This trial was funded by Biotest Pharma GmbH, Dreieich, Germany.

\section{Author Contributions}

Prof. Roland Devlieger and Dr. Buxmann contributed equally to this article. Dr. Wartenberg-Demand, Prof. Klaus Friese, Prof. Roland Devlieger, Dr. Horst Buxmann, Prof. Pal Siklós, Dr. Julia Jückstock, Prof. Giovanni Nigro, and Dr. Martin Enders were involved in concept and design of the study. Prof. Klaus Friese, Prof. Roland Devlieger, Dr. Horst Buxmann, Prof. Pal Siklós, Dr. Julia Jückstock, Prof. Giovanni Nigro, and Dr. Martin Enders assisted with data acquisition. Prof. Roland Devlieger, Dr. Horst Buxmann, Prof. Klaus Friese, Dr. Martin 
Enders, Dr. Wartenberg-Demand, Dr. Marlis Herbold, Dr. Gabriele Niemann, Dr. Joachim Schütze, Natascha Rippel, and Dr. Jörg Schüttrumpf contributed to analysis and interpretation of data. Prof. Roland Devlieger, Dr. Horst Buxmann, Prof. Klaus Friese, Prof. Pal Siklós, Dr. Julia Jückstock, Prof. Giovanni Nigro, Dr. Martin Enders, Dr. Wartenberg-Demand, Dr. Marlis Herbold, Dr. Gabriele Niemann, Dr. Joachim Schütze, Natascha Rippel, and Dr. Jörg Schüttrumpf revised and approved the manuscript. Data management, statistics, and medical writing were performed by GKM Gesellschaft für Therapieforschung $\mathrm{mbH}$, Munich, Germany; and project management, data management, and statistics were performed by J\&P Medical Research Ltd., Vienna, Austria, and ICRC-Weyer GmbH, Berlin, Germany.

\section{References}

1 Kenneson A, Cannon MJ. Review and metaanalysis of the epidemiology of congenital cytomegalovirus (CMV) infection. Rev Med Virol. 2007 Jul-Aug;17(4):253-76.

2 Townsend CL, Forsgren M, Ahlfors K, Ivarsson SA, Tookey PA, Peckham CS. Long-term outcomes of congenital cytomegalovirus infection in Sweden and the United Kingdom. Clin Infect Dis. 2013 May; 56(9):1232-9.

3 Kagan KO, Hamprecht K. Cytomegalovirus infection in pregnancy. Arch Gynecol Obstet. 2017 Jul;296(1):15-26.

4 Fowler KB, Boppana SB. Congenital cytomegalovirus (CMV) infection and hearing deficit. J Clin Virol. 2006 Feb;35(2):226-31.

5 Ludwig A, Hengel H. Epidemiological impact and disease burden of congenital cytomegalovirus infection in Europe. Euro Surveill. 2009 Mar 5;14(9):26-32.

6 Vauloup-Fellous C, Picone O, Cordier AG, Parent-du-Châtelet I, Senat MV, Frydman $\mathrm{R}$, et al. Does hygiene counseling have an impact on the rate of CMV primary infection during pregnancy? Results of a 3-year prospective study in a French hospital. J Clin Virol. 2009 Dec;46(Suppl 4):S49-53.

7 Revello MG, Tibaldi C, Masuelli G, Frisina V, Sacchi A, Furione M, et al. Prevention of primary cytomegalovirus infection in pregnancy. EBioMedicine. 2015 Sep;2(9):120510.

8 Rawlinson WD, Boppana SB, Fowler KB, Kimberlin DW, Lazzarotto T, Alain S, et al. Congenital cytomegalovirus infection in pregnancy and the neonate: consensus recommendations for prevention, diagnosis, and therapy. Lancet Infect Dis. 2017 Jun; 17(6):e177-88.

9 Shahar-Nissan K, Pardo J, Peled O, Krause I, Bilavsky E, Wiznitzer A, et al. Valaciclovir to prevent vertical transmission of cytomegalovirus after maternal primary infection during pregnancy: a randomised, doubleblind, placebo-controlled trial. Lancet. 2020 Sep 12;396(10253):779-85.

\section{Data Availability Statement}

All data on which the conclusions of the manuscript rely are included in this article and/or its online suppl. material files. Further enquiries can be directed to the corresponding author. The study protocol can be found at https://www.clinicaltrialsregister. $\mathrm{eu} / \mathrm{ctr}$-search/search?query=2007-004692-19.
10 Nigro G, La Torre R, Anceschi MM, Mazzocco M, Cosmi EV. Hyperimmunoglobulin therapy for a twin fetus with cytomegalovirus infection and growth restriction. Am J Obstet Gynecol. 1999 May;180(5):1222-6.

11 Buxmann H, Stackelberg OM, Schlößer RL, Enders G, Gonser M, Meyer-Wittkopf M, et al. Use of cytomegalovirus hyperimmunoglobulin for prevention of congenital cytomegalovirus disease: a retrospective analysis. J Perinat Med. 2012 Mar 27;40(4):43946.

12 Japanese Congenital Cytomegalovirus Infection Immunoglobulin Fetal Therapy Study Group. A trial of immunoglobulin fetal therapy for symptomatic congenital cytomegalovirus infection. J Reprod Immunol. 2012 Sep;95(1-2):73-9.

13 Nigro G, Adler SP, Gatta E, Mascaretti G, Megaloikonomou A, La Torre R, et al. Fetal hyperechogenic bowel may indicate congenital cytomegalovirus disease responsive to immunoglobulin therapy. J Matern Fetal Neonatal Med. 2012 Nov;25(11):2202-5.

14 Nigro G, Adler SP, Parruti G, Anceschi MM, Coclite E, Pezone I, et al. Immunoglobulin therapy of fetal cytomegalovirus infection occurring in the first half of pregnancy: a case-control study of the outcome in children. J Infect Dis. 2012 Jan 15;205(2):21527.

15 Blazquez-Gamero D, Galindo Izquierdo A, Del Rosal T, Baquero-Artigao F, Izquierdo Mendez N, Soriano-Ramos M, et al. Prevention and treatment of fetal cytomegalovirus infection with cytomegalovirus hyperimmune globulin: a multicenter study in $\mathrm{Ma}$ drid. J Matern Fetal Neonatal Med. 2019 Feb;32(4):617-25.

16 Nigro G, Adler SP; Congenital Cytomegalic Disease Collaborating Group. High-dose cytomegalovirus (CMV) hyperimmune globulin and maternal CMV DNAemia independently predict infant outcome in pregnant women with a primary CMV infection. Clin Infect Dis. 2020 Sep 12;71(6):1491-8.
17 Nigro G, Adler SP, La Torre R, Best AM; Congenital Cytomegalovirus Collaborating Group. Passive immunization during pregnancy for congenital cytomegalovirus infection. N Engl J Med. 2005 Sep 29;353(13): 1350-62.

18 Revello MG, Lazzarotto T, Guerra B, Spinillo A, Ferrazzi E, Kustermann A, et al. A randomized trial of hyperimmune globulin to prevent congenital cytomegalovirus. N Engl J Med. 2014 Apr 3;370(14):1316-26.

19 Hughes B. Randomized trial to prevent congenital cytomegalovirus (CMV). Open Forum Infect Dis. 2019;6:1000-1.

20 Kagan KO, Enders M, Schampera MS, Baeumel E, Hoopmann M, Geipel A, et al. Prevention of maternal-fetal transmission of cytomegalovirus after primary maternal infection in the first trimester by biweekly hyperimmunoglobulin administration. Ultrasound Obstet Gynecol. 2019 Mar;53(3): 383-9.

21 Visentin S, Manara R, Milanese L, Da Roit A, Forner G, Salviato E, et al. Early primary cytomegalovirus infection in pregnancy: maternal hyperimmunoglobulin therapy improves outcomes among infants at 1 year of age. Clin Infect Dis. 2012 Aug;55(4):497503

22 Rawlinson WD, Hamilton ST, van Zuylen WJ. Update on treatment of cytomegalovirus infection in pregnancy and of the newborn with congenital cytomegalovirus. Curr Opin Infect Dis. 2016 Dec;29(6):615-24.

23 Cahill AG, Odibo AO, Stamilio DM, Macones GA. Screening and treating for primary cytomegalovirus infection in pregnancy: where do we stand? A decision-analytic and economic analysis. Am J Obstet Gynecol. 2009 Nov;201(5):466-7.

24 Griffiths PD, Baboonian C. A prospective study of primary cytomegalovirus infection during pregnancy: final report. Br J Obstet Gynaecol. 1984 Apr;91(4):307-15. 
25 Stagno S, Whitley RJ. Herpesvirus infections of pregnancy. Part I: cytomegalovirus and epstein-barr virus infections. N Engl J Med. 1985 Nov 14;313(20):1270-4.

26 Ahlfors K, Ivarsson SA, Harris S. Report on a long-term study of maternal and congenital cytomegalovirus infection in Sweden. Review of prospective studies available in the literature. Scand J Infect Dis. 1999;31(5): 443-57.

27 Rawlinson W, Scott G. Cytomegalovirus. A common virus causing serious disease. Aust Fam Physician. 2003 Oct;32(10):789-93.

28 Pass RF, Fowler KB, Boppana SB, Britt WJ, Stagno $S$. Congenital cytomegalovirus infection following first trimester maternal infection: symptoms at birth and outcome. J Clin Virol. 2006 Feb;35(2):216-20.

29 Enders G, Daiminger A, Bäder U, Exler S, Enders M. Intrauterine transmission and clinical outcome of 248 pregnancies with primary cytomegalovirus infection in relation to gestational age. J Clin Virol. 2011 Nov;52(3):244-6.
30 Feldman B, Yinon Y, Tepperberg Oikawa M, Yoeli R, Schiff E, Lipitz S. Pregestational, periconceptional, and gestational primary maternal cytomegalovirus infection: prenatal diagnosis in 508 pregnancies. Am J Obstet Gynecol. 2011 Oct;205(4):342-6.

31 Picone O, Vauloup-Fellous C, Cordier AG, Guitton S, Senat MV, Fuchs F, et al. A series of 238 cytomegalovirus primary infections during pregnancy: description and outcome. Prenat Diagn. 2013 Aug;33(8):751-8.

32 Boerma T, Ronsmans C, Melesse DY, Barros AJD, Barros FC, Juan L, et al. Global epidemiology of use of and disparities in caesarean sections. Lancet. 2018 Oct 13; 392(10155):1341-8.

33 Delnord M, Blondel B, Zeitlin J. What contributes to disparities in the preterm birth rate in European countries? Curr Opin Obstet Gynecol. 2015 Apr;27(2):133-42.

34 Smit GSA, Padalko E, Van Acker J, Hens N, Dorny P, Speybroeck N, et al. Public health impact of congenital toxoplasmosis and $\mathrm{cy}$ tomegalovirus infection in Belgium, 2013: a systematic review and data synthesis. Clin Infect Dis. 2017 Aug 15;65(4):661-8.

35 Smit GSA, Abrams S, Dorny P, Speybroeck N, Devleesschauwer B, Hutse V, et al. The seroprevalence of cytomegalovirus infection in Belgium anno 2002 and 2006: a comparative analysis with hepatitis a virus seroprevalence. Epidemiol Infect. 2019 Jan; 147:e154.

36 Prince HE, Lapé-Nixon M. Role of cytomegalovirus (CMV) IgG avidity testing in diagnosing primary CMV infection during pregnancy. Clin Vaccine Immunol. 2014 Oct; 21(10):1377-84.

37 Hamprecht K, Kagan KO, Goelz R. Hyperimmune globulin to prevent congenital CMV infection. N Engl J Med. 2014 Jun 26; 370(26):2543.

38 Cosmi E, Mazzocco M, La Torre R, Ligi P, Sali E, Nigro G. (Therapy or prevention of fetal infection by cytomegalovirus with immunoglobulin infusion in pregnant women with primary infection). Acta Biomed Ateneo Parmense. 2000;71(Suppl 1):547-51. 